\title{
Illness understanding in children and adolescents with heart disease
}

\author{
G R Veldtman, S L Matley, L Kendall, J Quirk, J L Gibbs, J M Parsons, J Hewison
}

\begin{abstract}
Aims-To evaluate illness knowledge and understanding in children and adolescents with congenital and acquired heart disease, and whether the degree of understanding is related to age, sex, or complexity of the heart disease.

Design-Prospective cohort study.

Setting-Tertiary paediatric cardiac centre.

Methods-Patients' understanding of their congenital heart disease was assessed in a representative sample of volunteers aged between $7-18$ years using semistructured interviews based upon Leventhal's illness representation model.

Results-63 of 69 interviews were suitable for analysis. There were similar numbers of boys and girls and a wide distribution of heart defects. Only $30 \%$ of patients had a good understanding of their illness; $77 \%$ did not know the medical name of their condition, and 33\% had a wrong or poor understanding of their illness. Understanding was unrelated to age, sex, or the nature of the heart disease. Understanding of illness duration was significantly related to age, but not to sex or to the nature of the disease.

Conclusions-Illness understanding is poor in children and adolescents with heart disease, and many have an entirely wrong concept of their disease. Intensified efforts to ensure better patient and parental understanding are needed.

(Heart 2000;84:395-397)
\end{abstract}

Keywords: understanding illness; children; heart disease

Accurate understanding of chronic illness in patients of any age is associated with less distress, less confusion, improved satisfaction with medical care, better compliance with treatment, and an improved emotional state, ${ }^{1}$ all key factors for good health related quality of life. In chronic illnesses such as diabetes mellitus and asthma, illness knowledge has been reported to be poor. ${ }^{2}$ Some studies suggest that children with chronic illnesses do not know more about their condition or their body than their healthy counterparts. ${ }^{3}$ Traditionally, medical professionals have entrusted the parents of children with chronic illnesses with the task of imparting knowledge about the illness to their child. This practice assumes that parents understand the illness and that they pass on their knowledge in a manner appropriate for the individual child. However, parents often do not understand and may forget what they have been told. ${ }^{4}$

It has been argued ${ }^{5}$ that the emotional stress

Department of Paediatric Cardiology, Yorkshire Heart Centre, Leeds General Infirmary, Great George Street, Leeds LS1 3EX, UK G R Veldtman S L Matley

L Kendall

J Quirk

J L Gibbs

J M Parsons

J Hewison

Correspondence to: Dr Gibbs

email: jgibbs@cwcom.net

Accepted 24 May 2000 identified from the Yorkshire Heart Centre congenital heart disease database and were invited either by letter or by telephone call, before a routine outpatient visit, to participate in an interview. Semistructured interviews were conducted based on Leventhal's illness representation model, ${ }^{6}$ which was developed to explore the beliefs children hold of their illness. Adolescents were interviewed separately without their parents, whereas the younger children were given the choice of having their parents present during the interview. Interviews were conducted in a quiet room decorated specifically for adolescents, and the interviewer was dressed informally. In the younger age group, the interviews were carried out in the home environment whenever possible. Free conversation was encouraged, using open ended questions.

The following questions were asked: what was the medical name of their condition; what was wrong with their heart; how long did they think they had had the condition; how long were they likely to have the condition; how was their heart likely to affect them in the future. The interviews were recorded and subsequently transcribed.

Standard methods of content analysis were applied to the transcribed interviews, to provide categories for coding. ${ }^{6}$ Five per cent of the transcripts were double coded by a second evaluator to ensure coding reliability. High levels of rater agreement were achieved. Any differences in coding were resolved through discussion.

Knowledge related to name of diagnosis and ideas about what was wrong with the heart 
were assessed on a three point scale of wrong/poor explanation, partial explanation, and good explanation. The scale was constructed from identified criteria provided by the cardiologists.

Ethics approval was obtained from the United Leeds Teaching Hospitals ethics committee. Informed, written consent was obtained from both parents and patients.

DATA ANALYSIS

We used $\chi^{2}$ tests to assess whether the sex of the child affected illness understanding, and the Fisher's exact test to assess whether understanding was related to disease complexity. Student's $t$ test was used to assess whether age was related to knowledge of diagnosis name, and whether an understanding of the time line of the illness was a function of age. Analysis of variance (ANOVA) was used for comparing knowledge of illness and understanding of the time line at different ages.

\section{Results}

RECRUITMENT

Of 120 families contacted, 69 children and adolescents (58\%) agreed to be interviewed. Recruitment rate was better with a personal telephone call $(97 \%)$ than with a letter of invitation (44\%). Data could not be used in six patients because of a combination of factors, including problems with recording quality, early termination of interviews as a result of previous transport arrangements, and interview technique. There were 30 boys and 33 girls, ranging in age from 7-18 years (median 13 years). Their cardiac anomalies included isolated pulmonary stenosis, atrial septal defect, patent arterial duct, ventricular septal defect, tetralogy of Fallot, more complex cyanotic heart disease both with and without previous surgical treatment, acquired cardiomyopathy, and arrhythmias.

\section{ILLNESS UNDERSTANDING}

Only $14(22 \%)$ of the patients knew their diagnoses by name; $23(36 \%)$ had a wrong or poor understanding of the nature of their cardiac abnormality, 21(33\%) had a partial understanding, while only $19(30 \%)$ had a good understanding of their illness.

Examples of answers falling into each of the categories of understanding were:

(1) Wrong/poor explanation: A 13 year old with mitral atresia, double outlet right ventricle, banded pulmonary artery, awaiting cavopulmonary shunt operation: "I've got half a heart and it's got a hole in it and it's upside down."

(2) Partial explanation: A 14 year old with pulmonary regurgitation related to previous surgery for right ventricular outflow obstruction, awaiting homograft replacement of the pulmonary valve: "I know the valve leading to my heart is narrow and there is leaking from it."

(3) Good explanation: A 17 year old with repaired tetralogy of Fallot and complex arrhythmias: "When I was 3 I had heart surgery for a hole in my heart and narrow- ing of the arteries. They patched up the hole. As far as I know I've been fine since. As far as I know the artery isn't too wide and the two electrical centres are not coordinating properly".

After categorisation of cardiac anomalies into simple defects, which would not normally be associated with long term morbidity or mortality (pulmonary stenosis, atrial septal defect, arterial duct, and small ventricular septal defect), and more complex anomalies with potential for late morbidity (aortic stenosis, tetralogy of Fallot, mitral valve disease, complex disease, and cardiomyopathy), there was no significant relation between level of understanding and the patient's age, sex, or complexity of disease. Understanding of the time line of the illness, however, improved with increasing age; the mean age of those with good understanding was 15 years and the mean age of those with poor understanding was 10.5 years $(\mathrm{p}<0.001)$.

\section{Discussion}

It is the usual practice in cardiac centres to explain a patient's heart disease and its short and long term implications in lay terms, often with the use of simple diagrams, at the time of the initial diagnosis. Repeated explanation is often given on subsequent consultations but no formal assessment of understanding of the information given is made. Semistructured interviews offer an informal and open forum for patients to express their beliefs regarding their health and allow the interviewer some quantitative assessment of the individual patient's understanding. Our interviews were conducted along the guidelines described by Leventhal and colleagues. ${ }^{7}$ These guidelines were used to "describe how people as active agents, interpret and represent the information they receive about health threats from outside sources and from their bodies, and how their subsequent actions depend upon their understanding of that information".

Less than a quarter of our patients knew their diagnosis by name. This lack of knowledge was not related to age, sex, or complexity of condition. About one third of the children had a good conceptual understanding of their condition, but one third had either a completely wrong or a poor understanding of their illness. The lack of knowledge about diagnosis could have important implications upon a child's ability to relay essential information at times of medical emergency, when others are not available to provide this. A lack of basic diagnosis could lead to dangerous assumptions being made about emergency intervention. As children grow older, expectations that they will play an increasing role in the management of their condition begin to be established. The concept of children taking increasing responsibility for their own care is undermined by the absence of their ability to relay a basic explanation of the diagnosis.

Understanding of illness time line was related to age, reflecting conceptual and cognitive development as a function of age. Past researchers have shown that some children 
have a good understanding of the future implications of their illness, but found no clear pattern in terms of age differences in acquiring this knowledge base. The findings of the present study suggest that the older the children, the more developed were their ideas about the impact of the illness upon their future. The difference appeared to be largely attributable to stages of cognitive development, rather than reflecting the tendency of adults to avoid discussing emotive future issues with the younger children. It was noted that even within families which took a very open and frank approach to information about the condition, it still appeared that the understanding of the illness time line was related more to age than to issues of overprotection or lack of discussion.

There are multiple reasons for poor illness knowledge in young patients with chronic disease. Although we did not specifically aim to identify these in our study, some of the factors have been elucidated before. ${ }^{1}$ Poor understanding of normal anatomy and physiology in both parents and the patients may be an important factor making subsequent comprehension of illness difficult. Inadvertent use of jargon and overtechnical explanations of anatomy or physiology by specialists are likely to compromise effective transfer of knowledge. Patients forget a large proportion of what they are told about their illness, even of those aspects that they originally understood, ${ }^{4}$ and over many years a patient's inaccurate concepts may be magnified. In patients with congenital heart disease subtle developmental delay may also contribute to poor knowledge. ${ }^{8}$

Before this study we felt that our policy for providing information to patients and their parents was adequate, but the study shows that our patients' understanding of their disease is very limited. Counselling families on the subject of congenital heart disease can be time consuming, and assessment of the effectiveness of counselling even more so. There is good evidence to suggest that quality of life in terms of anxiety, "coping" with disease, satisfaction with treatment, and frequency of hospital admission in chronic illness are enhanced by good understanding of the condition. There can be no doubt that these aspects of quality of life for patients with congenital heart disease can be improved by intensified, audited efforts to ensure better understanding. Such a process is likely to have important resource implications for centres dealing with congenital heart disease. The results of the study must also be considered with regard to the wider issues of children's and adolescent's rights to information, their increasing involvement in decision making processes, and their consent to treatment. ${ }^{9}$

This study was supported by the Children's Heart Surgery Fund. We are also grateful for the statistical assistance of Ms Victoria Allgar of the United Leeds Teaching Hospitals Department of Research and Development.

1 Matley SL. Understanding, beliefs, and behaviour: a study of children with congenital heart defects. Leeds: University of Leeds, 1997:19-24. [Doctoral thesis.]

2 Eiser C, Patterson D, Tripp JH. Illness experience and children's concepts of health and illness. Child Care Health Dev 1984;10:157-62.

3 Eiser C, Town C, Tripp JH. Illness experience and related knowledge amongst children with asthma. Child Care Health Dev 1987;14:11-24.

4 Ley P. Improving patients' understanding, recall, satisfacLey P. Improving patients understanding, recall, satisfac-
tion and compliance. In: Broome A, ed. Health psychology. London: Chapman and Hall, 1989.

5 Nagera H. Children's reactions to hospitalization and illness. Child Psychol Hum Dev 1978;9:3-19.

6 Moser EA, Kalton G. Survey methods in social investigation. London: Gower, 1979.

7 Leventhal H, Nerenz D, Steele DJ. Illness representations and coping with health threats. In: Baum A, Taylor SE, Singer JE, eds. Handbook of psychology and health, vol IV. Social psychological aspects of health. New Jersey: Erlbaum, 1984.

8 Garson A, Williams RB, Reckless J. Long-term follow-up of patients with tetralogy of Fallot: physical health and psychopathology. F Pediatr 1974;85:429-33.

9 Alderson P. Children's consent to surgery. Buckingham: Open University Press, 1993. 